\title{
The subjective view of teachers: the connection between emotional burnout and the quality of the educational process
}

\author{
Olga Vagaeva $^{1 *}$, Irina Efremkina ${ }^{1}$, Elena Liksina ${ }^{1}$, Valerii Liusev ${ }^{1}$, and Natalia Osipova ${ }^{1}$ \\ ${ }^{1}$ Penza State Technological University, Department of Pedagogy and Psychology, Penza, Russia
}

\begin{abstract}
In Russia, the work of teachers at all levels of the education system is currently subject to increased and often contradictory and frequently changing requirements. Analysis of the literature on the research problem allowed revealing a contradiction between declaring the importance of a teacher's professional activity, on the one hand, and on the other hand, increasing responsibilities, reporting, psychoemotional tension of pedagogical work, and insufficient interest in the subjective assessment of the current situation by very teachers. The purpose of the present study was to identify the degree of emotional burnout among teachers and the subjective perception by teachers of the relationship between emotional burnout and the quality of the educational process. The study used survey methods, testing using a specially developed form and a Questionnaire to identify the level of professional burnout and deformation, the so-called Maslach Burnout Inventory (MBI) in the modification of O. Polyakova. The conducted study has shown that the problem of emotional (professional) burnout of teachers exists in educational organizations at all levels. However, the focus of this study has been shifted from the fact of teachers' emotional burnout to the subjective perception by teachers of their emotional burnout as a predictor of the educational process quality. The study has allowed revealing the severity of emotional (professional) burnout components, such as emotional exhaustion and reduction of personal achievements. Psychoemotional tension, stress, feelings of depression and fatigue, which can be considered as manifestations of professional burnout, are associated by the interviewed teachers with irregular working hours, a significant range of noncore activities, and a high level of responsibility, which, in turn, worsen the quality of the educational and upbringing process. Keywords: emotional (professional) burnout, emotional exhaustion, depersonalization, reduction of personal achievements.
\end{abstract}

\section{Introduction}

Currently, the importance and instability of the professional activity of a teacher, his role in the training and upbringing of the younger generation are declared at the level of state institutions. The very concept of teacher's professionalism "begins to be considered in the

\footnotetext{
${ }^{*}$ Corresponding author: yurmashevj@inbox.ru
} 
context of the extent to which the teacher can develop the student's subjective potential, and provide conditions for his personal growth." [1]

At the same time, the influence of contradictory emotional and stressful factors on the emotional sphere of the teacher is noted, which causes increased emotional stress, deterioration of health, neuroses, and psychosomatic diseases [1-3]. But in teachers, these violations are "transformative in nature, i.e. the psychological ill-health of the teacher is reflected both on students and their parents, and therefore this problem becomes even more widespread" [4], becoming the cause of pedagogical mistakes and misjudgments [5].

It is emphasized that "attempts to reform and modernize the education system will be ineffective if measures are not taken to solve the problems of the main subject of all these transformations, i.e. the teacher" [1].

Thus, the profession of a teacher is now considered a profession with an increased risk of neuropsychiatric disorders and a high probability of emotional burnout.

Burnout is considered as a "psychological syndrome in response to chronic interpersonal stressors at work" [6]. Its key aspects are exhaustion, a sense of cynicism and detachment as well as a sense of inefficiency and a lack of achievement [6]. Emotional and professional burnout is often seen as identical.

The problem of teachers' emotional burnout is not just a particular national problem. A significant number of works by foreign researchers are devoted to various aspects of teachers' emotional burnout studying the relationship of burnout with self-esteem and performance of teacher, emotional intelligence, indicators of students' well-being, satisfaction with teachers' work, and psychological well-being [7-11], etc.

The analysis of works on the research problem allowed revealing a contradiction between the declaration of the importance of the professional activity of a teacher and the growth of psychoemotional tension of pedagogical work, as well as the lack of interest in the subjective assessment of the current situation by very teachers.

The study aimed at identifying the degree of emotional burnout among teachers and the subjective perception by teachers of the relationship between emotional burnout and the quality of the educational process.

\section{Methods}

To achieve this goal, the authors used survey methods, testing using a specially developed form and a "Questionnaire to identify the level of professional burnout and deformation, namely, Maslach Burnout Inventory (MBI) in the modification of O. Polyakova" [12].

The research was based on 111 teachers of educational organizations of different levels in the city of Penza.

\section{Results}

Quantitative analysis of the results obtained using a developed questionnaire has shown the severity of professional burnout in the majority of respondents (Table 1).

As can be seen from the Table, the majority of respondents have indicators of emotional exhaustion at a threatening level. The overwhelming majority of teachers are characterized by "experiencing a low emotional background, indifference or emotional satiation" [12], which is considered as the main component of professional burnout. As noted by S. Maslach, this indicator has the highest factor load (0.84) [6]. 
Table 1. Indicators of emotional (professional) burnout among teachers

(in percentage to the number of respondents).

\begin{tabular}{|c|c|c|c|}
\hline $\begin{array}{c}\text { Indicators of emotional } \\
\text { (professional burnout) }\end{array}$ & $\begin{array}{c}\text { Low and below- } \\
\text { average level }\end{array}$ & $\begin{array}{c}\text { Medium and } \\
\text { above-average } \\
\text { level }\end{array}$ & High level \\
\hline Emotional exhaustion & 29.0 & 56.7 & 14.3 \\
\hline Depersonalization & 64.9 & 29.7 & 5.4 \\
\hline $\begin{array}{c}\text { Reduction of personal } \\
\text { achievements }\end{array}$ & 5.4 & 62.2 & 32.4 \\
\hline
\end{tabular}

However, the main proportion of respondents is characterized by low and below-average levels of depersonalization. This suggests that teachers when experiencing emotional exhaustion may try to consciously resist negative trends in their relationships with other people.

The indicator of reduction of personal achievements may indicate a tendency for teachers to negatively evaluate their professional achievements and successes, to reduce the range of their responsibilities, and to shed responsibilities. As the authors of the methodology point out, this burnout indicator shows "the degree of the self-assessment of burnout. This refers to a sense of incompetence and lack of achievement and productivity at work." [6]

It should be noted that any indicator that belongs to the medium or high range serves a rather serious alarm signal, and requires not only an analysis of the reasons for this situation but also the use of certain psychorehabilitation measures [6].

Thus, the analysis of the results obtained using the questionnaire has allowed concluding that the severity of emotional burnout components such as emotional exhaustion and reduction of personal achievements is quite indicative.

To identify subjectively significant factors of professional (emotional) burnout syndrome in teachers, and the relationship between burnout and the quality of teaching students, a questionnaire was used that included 10 questions.

At that, $79 \%$ of the respondents were women. All respondents had sufficient work experience in the field of education (at least 5 years) to be allowed to participate in the study.

When using the questionnaire, the following results have been obtained.

It should be noted that the situation today is characterized by a decrease in the quality of life of teachers, a low level of remuneration, and an increase in professional responsibility. Therefore, teachers' satisfaction with their professional activities was assessed as well.

Thus, when answering the question of whether or not the particular teacher is satisfied with their professional activity, the following results were obtained. Only $16 \%$ of the teachers surveyed were fully satisfied. The majority of respondents noted that they were more satisfied than dissatisfied with their professional activities. A fifth of the respondents were completely or partially dissatisfied (Fig. 1). 
- Not satisfied, $9 \%$

- Rather dissatisfied than satisfied $11 \%$

- Satisfied rather than dissatisfied,

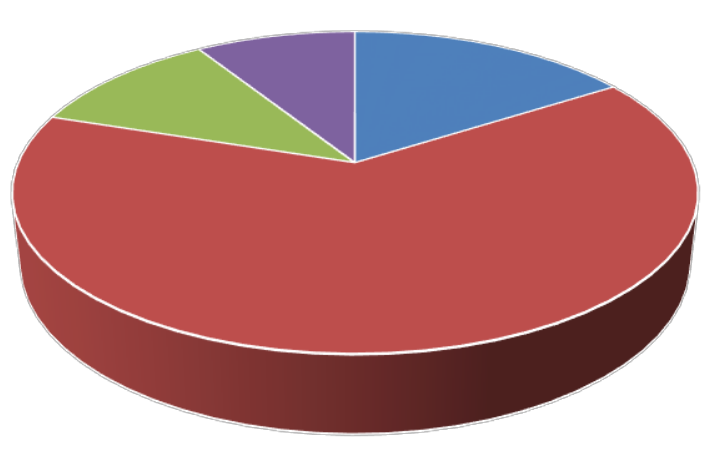
$64 \%$

- Satisfied, $16 \%$,

Fig. 1. Respondents' satisfaction with their professional activities (in \% of the number of respondents).

Also, the majority of respondents assessed their psychological and physical stress as high or very high (Fig. 2).

- High, 37\%

- Average, $19 \%$

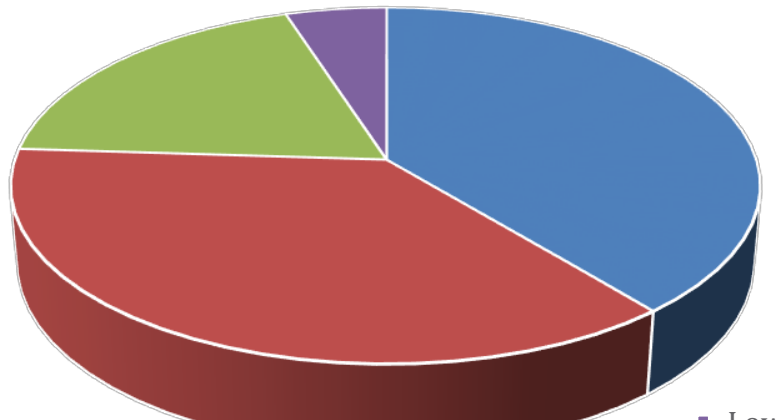

- Low, $5 \%$

- Very high $39 \%$

Fig. 2. Assessment of psychological and physical stress (in \% of the number of respondents).

It should be noted that teachers noted all kinds of activities, such as laying plans, writing reports, participating in projects, conducting research and writing articles, etc., rather than indicating to working directly with students.

The vast majority of teachers surveyed periodically experienced psychoemotional stress and tension in the course of their professional activities (Table 2). 
Table 2. Sensations in the course of professional activity (in $\%$ of the number of respondents).

\begin{tabular}{|l|c|}
\hline The sensations experienced by the respondents & \% of respondents \\
\hline Often physical stress & 22.5 \\
\hline Periodically psychoemotional tension, stress & 72.1 \\
\hline Psychological depression & 24.3 \\
\hline Constant fatigue & 29.7 \\
\hline
\end{tabular}

The analysis of harmful factors that, according to teachers, accompanied their activities was also carried out (Table 3 )

Table 3. Respondents' subjective assessment of harmful factors that accompany their professional activities (in \% of the number of respondents).

\begin{tabular}{|l|c|}
\hline Factors & \% of respondents \\
\hline Unfavorable microclimate in the team & 36.0 \\
\hline Irregular working hours & 53.1 \\
\hline Physical and psychological stress & 26.1 \\
\hline High level of responsibility for students & 37.8 \\
\hline High level of responsibility for learning materials & 38.7 \\
\hline Noncore activities (reports, control checks) & 61.3 \\
\hline Wages, inadequate to labor costs & 68.2 \\
\hline
\end{tabular}

The data presented in Tables 2 and 3, allow concluding that irregular working hours, a significant range of noncore activities that are not directly related to the educational process, a high level of responsibility can cause psychoemotional stress, tension, sensations of depression, and fatigue, which, in turn, can be considered as manifestations of professional burnout.

\section{Discussion}

According to $76.6 \%$ of respondents, the deterioration of the quality of the educational process is associated in one way or another with all these factors, as teachers have to constantly fight with them.

Foreign researchers highlight similar problems in the teachers' activity. The authors note that the constant experience of problematic situations without special work with them just leads to a response called burnout. At that, teachers with negative satisfaction with their professionalism have a higher chance of experiencing burnout [13]. This is consistent with the data obtained in the present study on the severity in teachers of such an indicator of emotional burnout as a reduction in professional achievements.

European researchers also note the connection of burnout syndrome as a negative result of professional activity with the long-term effect of stress resulting from repeated exposure to stressful events. The authors provide evidence that the main cause of burnout is a feeling of emotional exhaustion, which is characterized by physical and psychological fatigue in three different social contexts, namely, personal life, the workplace, and relationships with students [14].

Domestic research also notes an increase in these problems: to achieve an average salary, teachers have to additionally engage in tutoring, conduct additional hours that negatively affects both the quality of the work and the teachers' health [15]. They have to cope with a large amount of paperwork, often to the detriment of personal affairs and recreation that results in accumulation of "despair and resentment, irritation with professional activity factors, anxiety and self-disappointment" [16]. 
However, foreign researchers emphasize the need to study teachers' satisfaction with their work, calling it a key research area in the field of education, justifying this as benefits for both teachers and students, since "satisfied teachers demonstrate a high level of commitment to work" [17].

Researchers have identified similar problems for university academic staff, such as "low degree of freedom in the use of working time, lack of boundaries between working and personal time, excessive teaching load, and increase in the number of unscheduled tasks" [18].

\section{Conclusion}

Thus, the conducted study has allowed revealing the severity of components of emotional (professional) burnout such as emotional exhaustion and reduction of personal achievements, which the surveyed teachers associate with irregular working hours, a significant range of noncore activities, a high level of responsibility, which, in turn, worsen the quality of the educational process.

Conducting the comparative analysis of the features of emotional burnout of teachers working in schools, colleges, and universities is beyond the scope of the present study and may be the area of the next research aimed at clarifying the threatening factors.

\section{References}

1. L.M. Mitina, Lichnostnoye i professional'noye razvitiye uchitelya: strategii, resursy, riski [Personal and professional development of a teacher: strategies, resources, risks] (Nestor-Istoriya, Moscow, Saint Petersburg, 2018)

2. S.G. Akhmerova, Professional'naya deyatel'nost' i zdorov'ye uchitelya [Professional activity and health of a teacher] (Arsenal obrazovaniya, Moscow, 2010)

3. N.N. Malyarchuk, Bulletin of practical psychology of education, 7(3), 36-41 (2010)

4. M.A. Mokayeva, Pedagogical education in Russia, 3, 37-41 (2010)

5. G.F. Zaremba, Frustratsiya v professional'noy deyatel'nosti uchitelya nachal'noy shkoly i usloviya yeye preodoleniya [Frustration in the professional activity of an elementary school teacher and the conditions for overcoming it], Thesis (Moscow, 1982)

6. C. Maslach, M.P. Leiter, W. Schaufeli, The Oxford handbook organizational wellbeing (Oxford university press, Oxford, 2009).

https://doi.org/10.1093/oxfordhb/9780199211913.003.0005

7. Ye.Yu. Litvinova, M.A. Kharchenko, A.V. Pogodina, Institute of Psychology of the Russian Academy of Sciences. Organizational psychology and labor psychology, 3(2), 96-119 (2018)

8. Ç. Atmaca, F. Rızaoğlu, T. Türkdoğan, D. Yaylı, Teaching and Teacher Education, 90 (2020). https://doi.org/10.1016/j.tate.2020.103025

9. L.D. Prasojo, A. Habibi, M.F.M. Yaakob, R. Pratama, M.R. Yusof, A. Mukmininb, Suyanto, F. Hanuma, Journal Data in Brief, 30 (2020). https://doi.org/10.1016/j.dib.2020.105448

10. M.C. Martínez-Monteagudo, C.J. Inglés, L. Granados, D. Aparisi, J.M. GarcíaFernández, Personality and Individual Differences, 142, 53-61 (2019)

11. S.S. Braun, K.A. Schonert-Reichl, R.W. Roeser, Journal of Applied Developmental Psychology, 69, 101151 (2020). https://doi.org/10.1016/j.appdev.2020.101151 
12. O. Polyakova, Questionnaire for identifying the level of professional burnout and deformation. Maslach Burnout Inventory (MBI) (n.d.). Accessed on: December 20, 2020. [Online]. Available: http://www.prof-diagnost.org/prof_test/prof2.php

13. L.D. Prasojo, A. Habibi, M.F.M. Yaakob, R. Pratama, M.R. Yusof, A. Mukminin, Suyanto, F. Hanum, Heliyon, 6(1) (2020). https://doi.org/10.1016/j.heliyon.2019.e03144

14. C. Fiorilli, P. Benevene, S. De Stasio, I. Buonomo, L. Romano, A. Pepe, L. Addimando, Front. Psychol. 10, 2743 (2019). https://doi.org/10.3389/fpsyg.2019.02743

15. L.V. Klimenko, O.Yu. Posukhova, Educational Issues, 3, 36-67 (2018)

16. T.P. Bartosh, O.P. Bartosh, M.V. Mychko, Russian Psychological Journal, 16(3), 4558 (2019)

17. A. Pepe, L. Addimando, G. Veronese, Europe's Journal of Psychology, 13(3) (2017). https://doi.org/10.5964/ejop.v13i3.1389

18. R.N. Abramov, I.A. Gruzdev, E.A. Terentyev, Educational Issues, 1, 88-111 (2017). https://doi.org/10.17323/1814-9545-2017-1-88-111 